\title{
A Third Type of Distinction in the Treatise
}

\author{
Jani Hakkarainen
}

\begin{abstract}
Jani Hakkarainen is University Researcher in the School of Social Sciences and Humanities, University of Tampere, FI-33014 Tampereen yliopisto, Finland.

Email: jani.hakkarainen@uta.fi.
\end{abstract}

\begin{abstract}
In this paper, I resolve a potential contradiction between two of Hume's central tenets: that complex perceptions consist of simple perceptions and that distinct things are separable. The former implies that a complex perception is not separable from its constituent simple perceptions, as a change in its constituents destroys its identity. The latter entails that the complex perception is separable from these simple perceptions, since it is distinct from them. This is a contradiction. I resolve it by appealing to a third kind of distinction in addition to the two kinds Hume mentions: real distinctions and distinctions of reason. This third distinction is a partial distinction. I argue that just as the separability principle does not apply to distinctions of reason, neither does it apply to perceptions that are only partially distinct from other perceptions. Hence, the apparent contradiction is resolved.
\end{abstract}

\section{Introduction}

The following two principles are among Hume's fundamental tenets. On the one hand, Hume maintains that there are complex perceptions (impressions and ideas), ${ }^{1}$ that is, perceptions composed of other perceptions. On the other hand, he thinks that all distinct entities are separable. ${ }^{2}$ This includes perceptions (which are entities in Hume's view, as I will show below). According to the first principle, complex perceptions are composites consisting of other perceptions as their proper parts. These other perceptions are parts of the complex perceptions, but the latter are not parts of the former: proper part-hood is not a reflexive relation. (The primitive binary relation, part-hood, is reflexive). In addition, Hume thinks that composites are not separable from their parts (proper or not), for he holds that any change in their parts destroys their identity, strictly speaking (T 1.4.6.8; SBN 255-56; cf. T 1.1.5.4; SBN 14). ${ }^{3}$ Consequently, complex perceptions are not separable from the perceptions composing them. This is a result that conflicts with the second principle, which Don Garrett calls the "separability principle." ${ }^{\prime 4}$ Complex perceptions are distinct from each of the perceptions composing them because they are not identical with any one of these perceptions. So, by the separability principle, they should be separable from each of these 
distinct perceptions. However, the first principle implies that this is not the case. Hume's two principles thus entail that a complex perception is and is not separable from the perceptions composing it. This is a manifest contradiction.

In this paper, my intention is to salvage Hume's position by making these two principles consistent, at least when applied to the complex perceptions of extension or space. I shall argue that a complex perception of extension is merely "partially distinct" from the perceptions composing it and that there are good reasons to hold that the separability principle does not apply to entities that are only partially distinct. Hence, the contradiction is resolved. Part of the argument is that although Hume speaks merely about distinction when stating the principle, the principle holds only of really distinct entities.

The notion of a partial distinction is borrowed from David K. Lewis. ${ }^{5}$ Its Humean definition is as follows: $x$ is partially distinct from $y$ if and only if $x$ is not identical with $y$ and $x$ and $y$ share parts. I shall argue that all of Hume's complex perceptions of extension or space satisfy these two conditions: (1) they are not identical with any, some, or all of the simple perceptions constituting it, and (2) the complex perceptions share parts with the constituting simple perceptions. These shared parts are the constituting perceptions themselves. They both compose the complex perception (are its parts) and are their own (improper) parts. Improper part-hood as well as part-hood is a reflexive relation because improper part means that it and the whole have the same parts. Hence, a thing is its own improper part. In principle, this is not restricted to spatial parts, although my focus will be on the parts of the complex perceptions of extension (and properties of extension such as size and shape), which are spatial for Hume, as I will show below. If the most charitable interpretation of Hume's account of the complex perception of extension implies that the parts of the perception are partially distinct from the complex perception, then, of course, his system in the Treatise is compatible with the distinction. I will also limit my chief argument to perceptions of extension rather than to space itself. My reason for this restriction is that it is a controversial issue whether Hume commits himself to the existence of entities other than perceptions.

Admittedly, Lewis's notion of a "partial distinction" is anachronistic. To resolve the looming contradiction, a non-anachronistic notion would be preferable, but as I shall show below, Lewis's concept does best among alternatives. In addition, I am not maintaining that Hume recognized the category of partial distinctions. I only argue that his system in the Treatise is compatible with it, and it can be used to resolve the contradiction described earlier.

In order to make my main argument, I must first show that there are no alternative accounts of the distinction between a complex perception of extension and its constituting simple perceptions that resolves the contradiction. In the Treatise, Hume distinguishes between real distinctions and distinctions of reason. Accordingly, first I have to show that a complex perception is neither really nor rationally distinct from its constituting perceptions. To do so, it is necessary to explain Hume's understanding of real distinctions and distinctions of reason. Since Hume's discussion is brief, it cannot be understood without putting it in the context of the classification of distinctions that some philosophers claim to have found in scholastic Aristotelian philosophy and Descartes. Thus, I will outline this classification of 
distinctions in the paper. The important qualification of the separability principle - that it applies only to things that are really distinct, and that it is a reciprocal relation-is explained in the discussion of real distinctions.

The paper has the following structure. In section 1, I outline briefly the framework of the classification of distinctions (before Hume). Section 2 touches upon Hume's views on real distinctions and distinctions of reason. It is in this section that I show that the separability principle is limited to objects that are really distinct. Hume's account of the perception of extension is discussed in section 3. I advance my main argument in section 4 after arguing that a complex perception of extension is neither really nor rationally distinct from the perceptions composing it. My main argument is that a complex perception of extension shares parts with the composing perceptions because the latter are its proper parts as well as their own parts (parthood is reflexive). The complex perception is not, however, identical to these proper parts of it; that is, it is not identical to them merely collectively, but only when the proper parts are ordered in a certain manner.

\section{Framework for the Classification of Distinctions}

Recent scholars reflecting on the work of the scholastic Aristotelians as well as that of Descartes have developed an interpretative framework for understanding the different kinds of distinctions, in particular the difference between real distinctions and distinctions of reason. In what follows I will rely on their interpretations to lay out the positions in logical space. Whether these interpretations are historically accurate is not relevant to the present purposes, since my interest lies in using this logical space to understand Hume.

According to Richard Glauser, the classification of distinctions has a multifaceted history. ${ }^{6}$ There was a long and complicated debate on the subject in late scholastic Aristotelianism, among, for instance, Duns Scotus (1266-1308) and his followers, William of Ockham (c.1288-c.1348) and Francisco Suarez (1548-1617). On Suarez's interpretation, some scholastic Aristotelians defended the view that there is only one actual distinction or non-identity, which was accordingly termed a "real distinction," as contrasted with the rational, mental or conceptual distinction that is not an actual non-identity and originates in the intellect. ${ }^{7}$ Against this, Scotus and Suarez argued, according to the latter, that there is an intermediate distinction that is as actual as a real distinction (Suarez, 1.13, 1.16). Suarez claims that he and Scotus had different views about this distinction (Suarez, 1.13, 1.16). According to Suarez, Scotus argues for a formal distinction, which Suarez rejects, endorsing a modal distinction instead (Suarez, 1.13 and 16). On Richard Glauser's view, Descartes in the Principia Philosophia (Princ. 1.60-1.62) ${ }^{8}$ followed Suarez's steps in this respect, with his classification of distinctions into real distinctions, modal distinctions, and distinctions of reason (Glauser, "Descartes, Suarez and the Theory of Distinctions," 419). ${ }^{9}$

According to one of the leading scholars of scholastic Aristotelianism, Marilyn McCord Adams, it was a widely held assumption amongst medievals that a real distinction goes hand in hand with separability, understood as the logical possibility of separate existence. ${ }^{10}$ Glauser thinks that both Suarez and Descartes shared this assumption: for them, if A and B are really 
distinct, they are mutually separable (Glauser, 427-28; Descartes, Princ. 1.60). As Suarez puts the point, "this is usually called a distinction between thing and thing [res]" (Suarez, 1.1). Glauser emphasises that the modality involved in this separability is logical, delimited by the law of contradiction above all (Glauser, 428). This is so because by virtue of his extraordinary power, God can separate entities that are naturally inseparable, but according to Glauser's Suarez and Descartes, even God's extraordinary power is limited by the laws of logic (Glauser, 428). Thus two entities, A and B, might be naturally inseparable, but if God can separate them, they are really distinct (Glauser, 428). Accordingly, A and B are really distinct if it is logically possible that A exist without B and vice versa (Glauser, 428). Hence, in terms of the logical modality, A and B are existentially independent of one another.

This important result may be put as follows, without using the anachronistic term "symmetric" (and later "asymmetric"/“antisymmetric” when speaking about one-sided distinctions). As was seen just above, on Glauser's interpretation, a real distinction is reciprocal for Suarez and Descartes, a view which, however, was not universally accepted by every Schoolman according to McCord Adams (William Ockham, 17). Below I will show that Descartes's criterion for real distinctions is significant for understanding Hume. Descartes states that if A and B are really distinct, each can be clearly and distinctly conceived of as a complete thing without the other (Princ. 1.60).

On Glauser's account, in contrast with real distinctions, modal distinctions are not necessarily reciprocal: there are both one-sided and reciprocal cases of modal distinctions for Suarez and Descartes (Glauser, 425-26, 430). However, for both thinkers, the basic case is one-sided: if A is modally distinct from B, A is not separable from B, but B is separable from A (Glauser, 425-26; Descartes, Princ. 1.61). In Descartes's system this is the distinction that holds between a mode and its substance, for example, between a shape and the body possessing the shape (Glauser, 430). According to Glauser, this inseparability of the mode from the substance is logical: not even God, by his extraordinary power, can separate the mode from the substance without destroying the mode (Glauser, 425-26, 428-29, 436-37). The mode is thus existentially dependent ${ }^{11}$ on the substance, but the substance is existentially independent of the mode. For instance, the shape of a body is inseparable from, and existentially dependent on, the body, but not the other way around. Hence, for Glauser's Descartes, the way to tell whether there is a modal distinction between A and B is the following: human beings cannot clearly conceive of A without $\mathrm{B}$, although they are able to conceive of B without A (Glauser, 436-37; Descartes, Princ. 1.61). Speaking about human beings is an important restriction here, as Glauser emphasises. For God has not only an extraordinary, but also an incomprehensible power, in Descartes's view. In contrast with an extraordinary power, an incomprehensible power is not restricted by the eternal truths (for example, the laws of logic, which God himself has created). Hence, even if A is logically inseparable from B, as is a mode from its substance, it is possible for God to separate them. As this possibility arises by virtue of God's incomprehensible power, human beings cannot understand it (Glauser, 428-30, 436-37).

In addition to this basic one-sided modal distinction, there is the reciprocal modal distinction that holds, according to Glauser's Descartes, between two modes of the same 
substance, because each can be clearly conceived without the other, although neither can exist without the substance (Glauser, 430; Descartes Princ. 1.61).

For Glauser's Suarez and Descartes, a modal distinction must involve actual non-identity, because B is separable from A, and identicals must be inseparable. As noted above, according to McCord Adams, for the scholastics this is not true of distinctions of reason. A distinction of reason does not involve an actual distinction, that is, actual non-identity, but depends only on the operation of the intellect (McCord Adams, 19). ${ }^{12}$ So, if A and B are rationally distinct, they are really identical; in other words, they are aspects of one and the same thing. Descartes's example of a distinction of reason is between extension and matter (Glauser, 431). Descartes writes that it is not possible to conceive of $\mathrm{A}$ without $\mathrm{B}$, or B without $\mathrm{A}$, when $\mathrm{A}$ and $\mathrm{B}$ are rationally distinct from each other (Princ. 1.62).

McCord Adams claims that Scotus's concept of a formal distinction is not easy to understand, and its interpretation is complicated by the fact that there may be an essential difference between his earlier and later views (McCord Adams, 22, 26). Here I will concentrate on the sole feature of the earlier position that is necessary for my argument concerning Hume. This feature is that, according to McCord Adams, a necessary condition for A and B's being formally distinct is that A and B "are or are in what is really one thing (res)" (McCord Adams, 24). So, either they are really identical, or they exist in one and the same thing. Peter King's way of putting this is that Scotus's formal distinction holds between two ways ${ }^{13}$ a thing (res) can be (King, "Scotus on Metaphysics," 24). King's example is that the will is formally distinct from the intellect because they are both in the same thing, namely the soul (and yet, their definitions do not include each other) (King, 23). This brings formal distinctions close to distinctions of reason. Still, according to both McCord Adams and King, Scotus maintains that the distinction holds independently of the operation of the intellect: it is an actual distinction (McCord Adams, 24; King, 23). How it is so is not relevant to this paper.

There is textual evidence that Hume was aware of the late scholastic discussion. At T 1.1.7.17 (SBN 24), he speaks about "that distinction of reason, which is so much talk'd of, and is so little understood, in the schools." It is also highly likely, on general grounds, that he was familiar with Descartes's discussion of these distinctions in the Principia. However, there is no direct explicit evidence of this. That Hume did not explicitly signal his knowledge of the scholastic or Descartes's discussion of this topic does not entail that he was unaware of it. ${ }^{14}$ Still, it is best to proceed with caution. Thus, my discussion in this section merely provides the logical space that is necessary to make the case that the distinction between a complex perception of extension and its constituent perceptions is a third kind of distinction. Moreover, I shall limit myself to the claim that, in order to avoid an inconsistency, Hume's system in the Treatise requires the concept of a partial distinction in addition to the real distinction and the distinction of reason. I do not wish to argue that Hume was aware that there is a third kind of distinction. Moreover, I am not claiming that scholasticism influenced Hume's thinking on this topic. However, understanding the scholastic debate and Descartes's position, on McCord Adams's, King's and Glauser's account, can help us to understand Hume better by making us aware of the variety of positions one can take on these matters. 


\section{Real Distinction and the Distinction of reason}

Hume's accounts of real distinctions and distinctions of reason cannot be understood without understanding two things: his distinction between simple and complex perceptions and his principle of conceivability. Concerning the former, I will simply assume that the distinction between simple and complex perceptions is compositional (without committing myself to the claim that it is only compositional). Simple perceptions do not have proper parts, whereas complex perceptions are wholes that divide into proper parts, the minimal of which are simple perceptions.

Thus, Hume's distinction differs from Locke's corresponding distinction, which is not compositional. ${ }^{15}$ Note also that as will be seen below, it does not follow from this account of complex perceptions that their every property is reducible to the properties of simple perceptions. Furthermore, even if this interpretation does not hold as a general account of the distinction, it suffices for my argument that it correctly describes the relation between the complex perceptions of extension and the simple perceptions that are their proper parts.

Hume's "Conceivability Principle" ${ }^{16}$ states that conceivability ${ }^{17}$ entails possibility in the sense of "absolute," or "metaphysical," possibility (T 1.3.14.35; SBN 172). If I have an impression or idea of $x$, then it is absolutely, or metaphysically, possible that $x$ exists (T 1.2.2.8 and 1.3.7.3; SBN 32 and SBN 95). ${ }^{18}$ This does not entail that $x$ must be some entity that is not a perception. It may be an impression, for instance, if I infer from the idea of $x$ to the possible existence of $x$. Ideas represent their corresponding impressions. Absolute, or metaphysical, necessity is bound by the law of contradiction: if proposition $p$ is absolutely necessary, not- $p$ implies a contradiction. So, if not- $p$ does not entail a contradiction, $p$ is absolutely or metaphysically possible ( $\mathrm{T}$ 1.3.3.3, 1.3.6.1, 1.3.6.5, 1.3.9.10; SBN 79-80, 86-87, 89, 111). From this delimitation, it is obvious that Hume runs logical modality together with absolute or metaphysical modality. For instance, he thinks that demonstrative inferential links are absolutely, or metaphysically, necessary (T 1.3.3.3, 1.3.6.1; SBN 79-80, 86-87; EHU ${ }^{19} 4.1$ 2, 12.28; SBN 25-26, 164). In short, in the Treatise, Hume does not distinguish between logical, absolute, and metaphysical modality, but treats them all as a single modality.

Hume uses the term "real distinction" or its cognates only once in his works, and that passage (in the first Enquiry) is not very helpful. ${ }^{20}$ Usually, he speaks about distinction, distinctness, or difference without qualification. However, this does not mean that Hume did not recognize or use the notion of a real distinction. I will now show that he did. This argument begins by looking at the framework of distinctions that I outlined in section 1 . Recall that for Glauser's Suarez and Descartes, the two conditions for a real distinction are mutual separability and mutually independent existence, both of which interpreted in terms of logical modalities, which limits even God's extraordinary powers. The fact that real distinctions must meet these two conditions has the consequence that real distinctions are reciprocal for Glauser's Suarez and Descartes. The latter also has a test for knowing that A and B are really distinct from each other: they are separately conceivable in a clear and distinct manner. I will next take these two conditions and this test, and I will show that Hume subscribes to them with two qualifications: Hume applies the category of real distinctions to perceptions, which 
are beings for him, and he makes the logical, absolute, and metaphysical modalities equivalent. Let me begin with the mutual separability requirement.

That really distinct entities are mutually separable for Hume as well is shown by the fact that he distinguishes distinctions of reason from real distinctions by appealing to the separability principle. There are two places where Hume explicitly writes that the separability principle does not apply to distinctions of reason. First, in his discussion of distinctions of reason at the very end of $\mathrm{T} 1.1 .7$ (Of abstract ideas), he asks: "What then is meant by a distinction of reason, since it implies neither a difference nor separation?” (T 1.1.7.17; SBN 25). Secondly, when Hume discusses Spinoza and Spinoza's critics in T 1.4 .5 (Of the immateriality of the soul), he writes that an abstract mode of a substance is supposed to be not separable but only rationally distinct from the substance, as follows: "By an action we mean much the same thing, as what is commonly call'd an abstract mode; that is, something, which, properly speaking, is neither distinguishable, nor separable from its substance, and is only conceiv'd by a distinction of reason, or an abstraction" (T 1.4.5.26; SBN 245). Even if Hume is not presenting his own view in this last passage, he puts it in his own terms. These two quotes put it beyond reasonable doubt that Hume thinks that the separability principle does not apply to distinctions of reason.

Since the boundary between distinctions of reason and real distinctions is drawn by the separability principle, the separability principle has to apply to the latter. As Hume writes, "Our perceptions are all really different, and separable, and distinguishable from each other, and from every thing else which we can imagine” ( $\mathrm{T}$ 1.4.5.27; SBN 245-46; emphasis added). The term "different" may be read as a synonym for "distinct" in this passage because Hume follows the same usage in another passage discussing the two distinctions: "Our foregoing reasoning concerning the distinction of ideas without any real difference will not here serve us in any stead" ( $T$ 1.2.6.6; SBN 67). There is therefore textual evidence for the interpretation that the separability principle does apply to the real distinction. Indeed, the evidence supports the reading that the separability principle should be stated in terms of real distinctions, and that in the case of a real distinction, the distinction is reciprocal (the entities are different "from each other"). Hence, according to Hume, A and B-perceptions A and B, in particular-are really distinct from each other if and only if they are mutually separable, which is Suarez's and Descartes's first condition for a real distinction on Glauser's interpretation.

According to Glauser, their second condition is logically independent existence. Hume agrees with this condition as well, since he does not make any distinction between logical, absolute, and metaphysical modality (although there is the difference that Hume does not connect these modalities to God's powers). In order to see this, assume that the ideas of A and $B$ are really distinct from each other. Hence, by the separability principle, these two entities (A and B) are separately conceivable. By the conceivability principle, according to which conceivability entails absolute, or metaphysical, possibility, both A and B themselves and the ideas of A and B are existentially independent of each other; in other words, it is absolutely, or metaphysically, possible that they exist separately. This result means that Hume also endorses the condition of mutual existential independence: A and B (and their ideas) are really distinct from each other if they do not depend for their existence on each other. Hume thus 
follows Glauser's Suarez and Descartes in thinking that a real distinction is reciprocal. ${ }^{21} \mathrm{~A}$ further consequence is that Hume subscribes to Descartes's test (on Glauser's reading) for knowing that there is a real distinction between A and B: they are clearly and distinctly conceivable separately (that is, as complete entities).

Hume contrasts distinctions of reason with separate existences when he says that a distinction of reason is made between inseparable entities, as for example the color and the figure of a globe of white marble: according to Hume, the figure and the color "are in effect the same and undistinguishable” (T 1.1.7.18; SBN 25). He also writes, as I pointed out above, that a distinction of reason "implies neither a difference nor separation” (T 1.1.7.17; SBN 25). Hume, thus, understands the distinction of reason as a distinction made within one and the same entity or idea. When perceptions A and B are merely rationally distinct, A cannot be clearly and distinctly conceived without B, or B without A. It follows that the separability principle does not apply to distinctions of reason, since if A and B are actually identical, they are inseparable. Hume thus follows tradition, as interpreted by McCord Adams and Glauser, in his understanding of the distinction of reason.

\section{Hume on Extension or Space}

Hume's metaphysics of space and time in part 2 of Book 1 of the Treatise (Of the ideas of space and time) is notorious. This is not only because of Hume's denial of the infinite divisibility of space, which appears to be at odds with Euclidean geometry. It is also due to what seems to be his paradoxical view in $\mathrm{T} 1.2$, that extension is composed of what is unextended. Because Hume's statement of his view is subject to misunderstanding and objections, I will rely on the recent literature that puts understanding before criticism and shows Hume's metaphysics of space and time to have at least some plausibility, especially Lorne Falkenstein's account. ${ }^{22}$ Still, I will provide textual evidence for the main points.

According to Falkenstein's account, Hume holds that every perception of extension is complex. Simple perceptions (both impressions and ideas) cannot present extension because all spatially located simple perceptions (namely, colors and tactile qualities) are unextended in themselves. ${ }^{23}$ Every perception of extension is thus a complex perception, consisting of the unextended simple perceptions of colors or tactile qualities (for example, hardness or temperature) (Falkenstein, 67-69). ${ }^{24}$ This is confirmed by what Hume writes about perceiving two color spots in complete darkness: "as these perceptions are each of them simple and indivisible, they can never give us the idea of extension” (T 1.2.5.12; SBN 57-58). These simple perceptions are minima sensibilia: minima visibilia and minima tangibilia. Hume summarizes his view as follows:

I . . . have shewn that 'tis impossible to conceive extension, but as compos'd of parts, endow'd with colour or solidity. The idea of extension is a compound idea; but as it is not compounded of an infinite number of parts or inferior ideas, it must at last resolve itself into such as are perfectly simple and indivisible. These simple 
and indivisible parts, not being ideas of extension, must be non-entities, unless conceiv'd as colour'd or solid. (T 1.4.4.8; SBN 228) ${ }^{25}$

So, on Hume's view, these simple perceptions are not merely perceptions of what were commonly referred to as unextended "mathematical points" in contrast with extended "physical points" but are, instead, perceptions of colored or tangible mathematical points. In the following passage, Hume describes his system as a medium between two unacceptable extremes:

It has often been maintain'd in the schools, that extension must be divisible, in infinitum, because the system of mathematical points is absurd; and that system is absurd, because a mathematical point is a non-entity, and consequently can never by its conjunction with others form a real existence. This wou'd be perfectly decisive, were there no medium betwixt the infinite divisibility of matter, and the non-entity of mathematical points. But there is evidently a medium, viz. the bestowing a colour or solidity on these points; and the absurdity of both the extremes is a demonstration of the truth and reality of this medium. The system of physical points, which is another medium, is too absurd to need a refutation. A real extension, such as a physical point is suppos'd to be, can never exist without parts, different from each other; and wherever objects are different, they are distinguishable and separable by the imagination. (T 1.2.4.3; SBN 40)

Consider also Hume's words a little later: "the minutest parts we can conceive are mathematical points” ( $\mathrm{T}$ 1.2.4.21; SBN 46-47). That the minima sensibilia, that is, mathematical points, are unextended for Hume is corroborated by his geometrical definition of a point: “A point [is defined] to be what has neither length, breadth nor depth” (T 1.2.4.9; SBN 42).

Hume writes that "the idea of space or extension is nothing but the idea of visible or tangible points distributed in a certain order" (T 1.2.5.1; SBN 53; see also T 1.2.4.2; SBN 3940). Elsewhere he defines extension as the "order," “manner," "disposition," “composition," or arrangement of the perceptions of either colored or tangible unextended points, a feature of a complex perception ( $\mathrm{T}$ 1.2.3.5; SBN 34). The seeming paradox, then, is that extension is composed of what is unextended. How is this possible?

In order to understand Hume's view, let us consider the simplest possible case of a complex perception of extension, which is the perception of a line consisting of the perceptions of two colored or tangible points in adjacent locations-that is, having nothing between them. ${ }^{26}$ According to Falkenstein's account, the length (extension) of this line is not a function of the length (or extension) of its proper parts, but rather a function of their locations on the line (Falkenstein, 63). For example, the line from location (0) to point (1) has the length $1-0=1$. It is due to this function, and to the fact that points can mark locations in suitable complexes, that extension may consist of what is unextended..$^{27}$ 
As was seen just above, either color or tangibility makes mathematical points perceptible to the mind. It requires a further argument that when these simple perceptions are considered in themselves and separately from everything else, they do not present any spatial property in addition to a color or tactile quality. This argument is relatively straightforward and is supported by textual evidence. If only a single colored or tangible point, and nothing else, is present to the mind, extension cannot be present to the mind; the colored or tangible point is an unextended mathematical point. Hume defends his view as follows:

[L]et us take one of those simple indivisible ideas, of which the compound one of extension is form'd, and separating it from all others, and considering it apart, let us form a judgment of its nature and qualities. 'Tis plain it is not the idea of extension. For the idea of extension consists of parts; and this idea, according to the supposition, is perfectly simple and indivisible. (T 1.2.3.12-13; SBN 38)

Baxter has argued that extension and space are equivalent for Hume. ${ }^{28}$ If this is correct, then space cannot be present to the mind when only the simple perception of a single colored or tangible point is entertained. Because it is a reasonable assumption that Hume holds that any spatial property, such as location, adjacency, or distance to another object, presupposes space, there cannot be spatial properties without space. Hence, it is impossible that the simple perceptions of colored and tangible points, separately and in themselves, present any spatial property to the mind. So, in themselves they cannot, and do not, present spatial location: they acquire location only in a suitable complex. Thus, location is something that the simple perceptions of colors or tactile qualities present only derivatively. The same must hold, then, of the adjacency relation, which is also a spatial property.

The footnote in $\mathrm{T}$ 1.1.7.7 (SBN 20) does not undermine this interpretation, although Hume writes there that simple ideas may have different points or circumstances of resemblance (T note 5; SBN 637). Garrett has pointed out—rightly on my view — that simple ideas may have aspects because it is possible that they bear different resemblances to distinct ideas (Cognition, 63). The point is, however, that then they are not conceived in themselves, separately from everything else.

There is a further argument for the claim that adjacency, or contiguity, is a derivative property of simple perceptions. This argument rests on the fact that adjacency is a relation. Hume holds that conceiving a relation, that is, having a perception of it, presupposes a comparison between the perceptions of its relata. Concerning equality, for example, he observes that "since equality is a relation, it is not, strictly speaking, a property in the figures themselves, but arises merely from the comparison, which the mind makes betwixt them" ( $\mathrm{T}$ 1.2.4.21; SBN 46-47). Hence, the individual simple perceptions of colored and tangible points themselves cannot present any relational property, adjacency included. This is confirmed by the fact that according to Hume, ideas, and thus impressions, of relations are complex: “complex ideas may be divided into relations, modes, and substances” ( $\mathrm{T}$ 1.1.4.7; SBN 13). ${ }^{29}$ Comparison is also ruled out because they are each considered separately from everything else, including each other. 
That adjacency is a derivative property of the perceptions of colored and tangible points is also suggested by Hume's reply to the objection from "the necessity there wou'd be of penetration, if extension consisted of mathematical points” (T 1.2.4.6; SBN 41). He writes:

Taking then penetration in this sense, for the annihilation of one body upon its approach to another, I ask any one, if he sees a necessity, that a colour'd or tangible point shou'd be annihilated upon the approach of another colour'd or tangible point? On the contrary, does he not evidently perceive, that from the union of these points there results an object, which is compounded and divisible, and may be distinguish'd into two parts, of which each preserves its existence distinct and separate, notwithstanding its contiguity to the other? Let him aid his fancy by conceiving these points to be of different colours, the better to prevent their coalition and confusion. A blue and a red point may surely lie contiguous without any penetration or annihilation. (T 1.2.4.6; SBN 41)

In this passage, Hume says that whether two colored points are adjacent or not does not affect their nature as simple perceptions. Being contiguous to each other is only a derivative property of them. The same is true of location.

Hume's discussion of the vacuum at T 1.2.5 might complicate this result. There Hume speaks of an "invisible and intangible distance” ( $\mathrm{T}$ 1.2.5.16; SBN 59), which seems to suggest that there could be a relational spatial property, namely, distance, without space or extension. But according to Hume, just as "blindness and darkness afford us no ideas of extension, “'tis impossible that the dark and undistinguishable distance betwixt two bodies can ever produce that idea” (T 1.2.5.11; SBN 57).

We must be especially careful here. First, although Hume refers to the invisible and intangible distance, it is not certain that he thinks there can be an invisible and intangible distance. After all, he calls it “imaginary,” or "fictitious," and its opposite "real” (T 1.2.5.13, $\mathrm{T}$ 1.2.5.23, T 1.2.5.27; SBN 58, 62, 64). Moreover, his examples of this distance are of two colored and tangible points distant from each other that are seen and touched in complete darkness and without anything tangible between them (T 1.2.5.8-13; SBN 56-58). So, even if Hume thinks, and this is dubious, that these points are truly distant from each other, this does not entail that a single light spot in complete darkness, for example, presents true location in space, or any other spatial property, to the mind, though the spot seems to be located somewhere in the visual field. Hence, it seems to me that Hume's discussion of a vacuum does not undermine the interpretation that simple perceptions present spatial properties to the mind derivatively, rather than primitively, in Hume's theory. 


\section{Partial Distinctions}

\subsection{Complex Perceptions of Extension Are Neither Really Nor Rationally Distinct from Their Proper Parts}

Interpreted in this manner, Hume's views on space have significant implications. Let me focus first on Hume's complex perception of extension itself from the point of view of identity and distinctness, and afterwards discuss the distinction between the complex perception of extension and its constituent simple perceptions.

Hume's views on space imply that the complex perception of extension and the extension it presents are identical to each other. Moreover, the perception of this extension and the perceptions of its properties and features are aspects of one and the same complex perception. For example, the perception of the extension and the length of the line is an aspect of the perception of the line together with, say, its one-dimensionality in space, and it is identical with them. This is because visual and tangible complex perceptions are the simple perceptions of colors or tactile qualities that compose them, arranged in a certain way (Falkenstein, 68). In my illustration, the perception of the line is the perceptions of the two either colored or tactile points in the locations (0) and (1). A more complicated illustration would be the perception of a square with the side length of unit 1 . It is composed of the simple perceptions of four either colored or tangible mathematical points. The extension of the square, that is, its area (unit 1), its figure (square), and two dimensionality are aspects of, and identical to, its complex perception. So, these kinds of complex perceptions are identical to their proper parts ordered in a certain way. Extension or space is this arrangement or disposition of the simple visual or tangible perceptions (Falkenstein, 68). Extension and the properties and features, such as length and volume that a complex perception of extension presents are properties of the complex perception, which is composed of the simple perceptions of either colors or tactile qualities. A kind of relational conception of space follows from this: space is not some entity over and above extended entities. For instance, in the line example, the perception of its length (1) is not something really distinct from the two simple perceptions of colored or tactile points and their complex, a fourth entity in the picture. Therefore, the distinction between (a) the complex perception of extension, (b) the perception's extension, as well as (c) the properties and features of the extension, and (d) the simple visual or tactile perceptions ordered in a certain way is clearly a mere distinction of reason because, as was seen in section 2, a distinction of reason entails actual identity for Hume. The complex perception (a), its extension (b), and the (c) properties and features of the extension are one and the same. Hume must mean this identity rather than compositional simplicity when he speaks about "this simplicity" of "the body figur'd" in the context of the distinction of reason (T 1.1.7.18; SBN 25). So the complex perception (a), its extension (b), and the (c) properties and features of the extension can be distinguished from each other only by the understanding. Therefore my talk about aspects should be understood in the following manner. Aspects are features of things that are only rationally distinct from the things. So not only complex but also simple perceptions may have aspects in Hume's theory. This does not make simple perceptions qualitatively complex in themselves because according to Hume, the distinction of reason 
requires conceiving of similarity, whose perception, as a relation, requires having at least two ideas ( $\mathrm{T}$ 1.1.7.18; SBN 25). Thus, simple perceptions cannot have aspects when they are considered in themselves and separately from everything else.

I argue for the identity of a complex perception and its constituent simple perceptions arranged in a certain manner only in the case of the complex perceptions of extension. Whether it holds of every complex perception is a question that cannot be addressed here due to limitations of space. The answer to this question depends on the possibility that there is some relation, most likely a principle of association that unifies complex perceptions into individuals. For example, let me assume that there is a complex perception consisting of three simple perceptions $\mathrm{A}, \mathrm{B}$, and $\mathrm{C}$. If the complex perception is identical with $\mathrm{A}, \mathrm{B}$, and $\mathrm{C}$ unified by relation $\mathrm{R}$, then it is not identical with the mere plurality of $\mathrm{A}, \mathrm{B}$, and $\mathrm{C}$, but the plurality related by $\mathrm{R}$.

This does not entail, however, that there is a relation of identity between the complex perception of extension and its constituent simple perceptions - that is, that the perception of the line just is the perceptions of the two colored or tactile points separately or their plurality without any order. The reason this is so is that it is possible to conceive of the simple perceptions without conceiving the order constituting this particular complex perception. One can conceive the proper parts without conceiving the whole and without conceiving the order of the parts in the whole. The two points can be conceived of in themselves, separate from the conception of the line, its length, and each other. As we have seen, in themselves they present no location, or any (relational) spatial property whatsoever. So, in this respect, the two points are separable. As Hume writes, "from the union of these points there results an object, which is compounded and divisible, and may be distinguish'd into two parts, of which each preserves its existence distinct and separate, notwithstanding its contiguity to the other" (T 1.2.4.6; SBN 41). There is thus actual non-identity between the complex perception of extension and its constituent simple perceptions when the spatial order of the latter is not taken into account. This non-identity has the following consequences. First, the extension and the properties and features of the complex perception cannot be merely rationally distinct from their constituent simple perceptions because of the separability of the latter from the former (a distinction of reason entails inseparability). Secondly, this actual non-identity is not a real distinction. Real distinctions are reciprocal, but the separability of the proper parts of a complex perception of extension from the perception itself is one-sided. The complex perception of extension is not separable from its constituent parts. The extension, the properties and features of the extension of a complex perception, and the complex perception itself cannot be conceived of without conceiving of their constituent simple perceptions, since a whole, or composite, cannot be conceived without its proper parts. For instance, the line and its one-dimensional extension and length are not conceivable as that particular line and that particular instance of the length without conceiving of the two points, either colored or tangible. In this sense, the perception of the line and its length are inseparable from (though not identical with) the perceptions of the points. The negative conclusion from this is that the perception of the line and its length is neither merely rationally, nor really distinct from the perceptions of the two points in themselves. 
Following Falkenstein's and Garrett's accounts, I have been speaking consistently about the perceptions of extension or space in Hume's technical sense of "perception.” So this result concerns not only impressions but also ideas (mainly because of Hume's Copy Principle and his nominalism). Hence, if someone were to object to my argument by claiming that the idea of extension is separable from the simple ideas composing it, the objector would have to establish that Hume's account of the idea of extension differs from his view on the impression of extension in this respect.

\subsection{Complex Perceptions Are Partially Distinct from Their Proper Parts}

This negative result is not the only thing that can be concluded about the relationship between the complex perception of extension and its constituent simple perceptions. The positive conclusion is that the actual non-identity between them must be an instance of a third type of distinction. It involves both inseparability (but not identity), on the one hand, and separability, on the other hand: the complex perception of extension is inseparable from its constituent simple perceptions, but these simple perceptions are separable from the complex (by the separability principle and presenting no extension, spatial location, or relation in themselves). This kind of distinction is thus one-sided. It is also an actual non-identity because of the separability.

So, Hume's views of extension in the Treatise are compatible with a third kind of distinction with these characteristics. The next question is, how should this third kind of distinction be conceptualised? What would be the appropriate technical term for it? The outline of the framework of distinctions in section 1 is helpful here. Strictly speaking, the third kind of distinction is not a modal distinction, since a metaphysically robust modal distinction involves commitment to modes inhering in a substance, which Hume explicitly rejects ( $\mathrm{T}$ 1.4.3.6-7, 1.4.5.2, 1.4.5.6; SBN 221-22, 232, 234; see also T 1.4.5.21; SBN 242-43).

Still, could we say that the third type of distinction is a modal distinction in the looser sense, that certain properties of a perception of extension modify the complex perception-for example, the perception of the length of the line modifies the perception of the line? After all, properties of extension seem to be modifications of extension. It seems to me that the negative answer is the correct one because, strictly speaking, perceptions of particular spatial properties do not modify, but are identical with, a complex perception. In my example, the perception of the length of the line literally is the perception of the line. As such, the perception of the length is merely rationally distinct from the perception of the line. Besides, as was seen above, it is not the perceptions of the two points modified that happen to compose the perception of the line, but these perceptions of the points disposed in a certain manner (into the line complex). For instance, as I argued above, location does not, in itself, modify a simple colored or tangible perception: it is their derivative property in a visual or tangible complex perception. Thus, there cannot be a modal distinction between a complex perception (the line), its properties (length 1), and its minimal proper parts (the two points), even in this looser sense.

The same point, together with Hume's rejection of modes properly speaking, rules out the possibility that the third kind of distinction could be like Descartes's modal distinction 
between two modes of the same substance. According to Glauser's Descartes, the two modes are modally distinct from each other because they are modally distinct from the same substance. But it was just shown that Hume cannot accept the modal distinction between a mode and a substance. Therefore Descartes's modal distinction between the two modes of the same substance, on Glauser's reading, is not one that Hume would accept.

As was seen above, according to McCord Adams and King, one of the necessary conditions for Scotus's earlier version of a formal distinction between A and B is that they are either identical or exist in the same thing. This alone excludes the possibility of equating Hume's third type of distinction with Scotus's formal distinction on McCord Adams's and King's account. For if the extension of a complex perception, the properties of that extension, and the complex perception itself are compared with those simple perceptions in themselves that are the complex perception's minimal proper parts, it is seen that they are neither identical nor in the same thing. Rather, these simple perceptions are separable from the complex perception and its aspects.

As it seems that we cannot find any proper concept to characterize the type of distinction that exists between complex perceptions of extension and the constituting simple perceptions in the framework of distinctions outlined in section 1 here or in Hume's own vocabulary, we have to look for another alternative. That alternative can be found in Lewis's notion of a "partial distinction": $x$ and $y$ are partially distinct if and only if they have common parts. ${ }^{30}$ For example, a whole with two proper parts is partially distinct from these two proper parts because the proper parts are the parts of the whole, as well as being their own (improper) parts (since part-hood is reflexive). To describe the distinction we find in Hume between a complex perception of extension and the simple constituents of that perception in the Treatise, we need only add a further condition to Lewis's definition of a partial distinction: $x$ and $y$ must not be identical. This is to make the partial distinction irreflexive. Otherwise, as Lewis's part-hood is reflexive, an entity would share a part with itself (as its own part) and would be partially distinct from itself. This will not do. The distinction between an entity and itself is not actual nonidentity, and the third type of distinction should be actual non-identity (though the distinction is not a real distinction), because of the separability principle and the nature of visual and tactile simple perceptions in themselves. Thus, the definition of a partial distinction compatible with the Treatise account of extension is that $x$ and $y$ are partially distinct if and only if $x$ and $y$ are not (actually) identical and they have common parts.

Hume's complex perception of extension and those simple perceptions that compose it satisfy this definition. The complex perception of extension and the simple perceptions of which it is composed, any of them separately, some of them, or all of them together, are not identical. As I showed above, this type of complex perception is not merely the sum or aggregate of these simple perceptions, but the simple perceptions in their particular spatial order. ${ }^{31}$ The perception of the line is not identical with the perceptions of the two points separately or the perception of their plurality; it is identical with the perception of these two points in locations (0) and (1). Still they share parts. The simple perceptions are the proper parts of the complex perception, and they are their own parts (because part-hood is reflexive). They are also their own improper parts, since they do not have any other parts (simple 
perceptions do not divide into proper parts). For example, the perception of the line and its length of 1 are partially distinct from the perceptions of the two colored or tactile points composing the line; the perceptions of the points are the proper parts of the perception of the line (and its length) and their own (improper) parts.

This amended version of Lewis's concept of a partial distinction is exactly what is required to make sense of the distinction we find in the Treatise account of perceptions of extension: it is a intermediate distinction between a real distinction and a distinction of reason, and it involves actual non-identity. I have already established that a partial distinction is not a distinction of reason because it is not reflexive. Neither is it a real distinction, since it is not reciprocal: it does not involve mutual separability. There is, therefore, a third distinction, one between a real distinction, and a distinction of reason. It might be objected to this that the notion of a partial distinction smuggles in partial identity and makes identity a matter of degree. For Hume this would not do because he thinks that strict identity, which he calls "perfect simplicity and identity," is binary: $x$ and $y$ either are, or are not, perfectly identical ( $\mathrm{T}$ 1.4.2.39; SBN 205-206). This is revealed by the fact that the criterion of perfect diachronic identity is uninterruptedness and invariableness ( $T$ 1.4.2.30, T 1.4.2.33; SBN 201, 203). This criterion is not a matter of degree: an entity either is, or is not, uninterrupted and invariable. However, my account does not render perfect identity partial or a matter of degree because it includes the requirement that the order of the simple perceptions composing a complex perception of extension be taken into account. The complex perception of extension is identical to these simple perceptions disposed in a certain manner. For example, the perception of the line is not identical with the perceptions of the two colored or tactile points merely occurring together, but it is identical with the perceptions of those points in specific spatial locations. Perceiving this order is not a matter of degree.

Since my claim is restricted to the claim that the system of the Treatise is compatible with there being a third kind of distinction, that is, a partial distinction, it cannot be disputed by the lack of explicit textual evidence for Hume's recognition of this type of distinction. My main thesis, that there is nothing in the Treatise that would rule out the existence of partial distinctions, and that recognizing such distinctions can resolve a potential conflict in it, can be rejected only by denying the existence of perceptions in general. If there are no perceptions, there can be neither real distinctions nor the partial distinctions between them. Both are actual non-identities between existing things, and if there are no entities, there cannot be actual nonidentities between them. John Yolton's line of interpretation ${ }^{32}$ denies the existence of perceptions, and my intention is not to dismiss it; however, I do believe that it suffers from the serious problem that there is explicit, compelling textual evidence against it, for there are passages that clearly support the opposite interpretation. Hume's view in the Treatise is that there are perceptions:

Let us fix our attention out of ourselves as much as possible: Let us chace our imagination to the heavens, or to the utmost limits of the universe; we never really advance a step beyond ourselves, nor can conceive any kind of existence, but those 
perceptions, which have appear'd in that narrow compass (T 1.2.6.8; SBN 67; see also T 1.2.6.2, T 1.4.5.10; SBN 66, 235). ${ }^{33}$

One of Hume's reasons for this view is that he takes presence to the mind to be sufficient for existence; he does not require that existing things be concrete, extramental, spatio-temporal entities (T 1.4.5.10; SBN 235). Regarding Yolton's account of perceptions as acts rather than objects, this is too complicated to discuss here. Fortunately, such a discussion is not necessary. My chief argument for the partial distinction assumes only that Hume's distinction between simple and complex perceptions is compositional, and I do not see any reason in principle why this assumption could not be accommodated with an account of perceptions as acts (or mental objects, contents or states). The inseparability of a complex perception of extension from its constituent simple perceptions and the separability of the latter from the former still holds whether these perceptions are acts, objects, contents, or states.

\section{Conclusion and a Consequence}

Hume holds two tenets that appear to produce a contradiction: complex perceptions consist of simple perceptions and distinct entities are separable. The first principle entails that a complex perception is inseparable from its constituent simple perceptions, since Hume thinks that a composite is inseparable from its simple parts (there cannot be a change in the parts while the composite remains the same). According to the second principle, the complex perception is separable from its constituent simple perceptions because they are distinct, that is, not identical, and perceptions are entities. Hence, the complex perception both is and is not separable from its constituent simple perceptions. This is a contradiction.

In this paper, I have argued that to make Hume's account of our perception of extension consistent, we have to recognize a third kind of distinction that shares some features with the two distinctions he explicitly acknowledges. Like real distinctions, partial distinctions involve actual non-identity, and like distinctions of reasons, partial distinctions do not require actual separability. The complex perception of extension is merely partially distinct from its constituent simple perceptions of colors or tactile qualities. As such, the second principle, Hume's separability principle, does not apply to it. For the separability principle applies only when there is a real distinction: it holds only of really distinct entities.

One of Hume's central tenets is that there cannot be absolutely or metaphysically necessary connections between distinct entities, perceptions included. If my analysis of the distinction between perceptions of extension and the simple perceptions which are their parts is correct, this tenet must be qualified. For if my account is correct, there are absolutely, or metaphysically, necessarily connected distinct entities, namely, entities that are partially distinct, which is actual nonidentity. From my account, it follows that the extension, and the properties and features of the extension of an actually existing complex perception, are absolutely, or metaphysically, necessarily connected to each and every simple perception of colors or tactile points constituting that complex perception. The argument for this is the following. 
The Humean definition of an absolutely, or metaphysically, necessary connection is that A is absolutely, or metaphysically, necessarily connected to B if and only if it is not absolutely or metaphysically possible to conceive A without B (doing so implies a contradiction). That this is Hume's understanding of an absolutely, or metaphysically, necessary connection is substantiated by his statement in the context of causation: "Such a connexion wou'd amount to a demonstration, and wou'd imply the absolute impossibility for the one object not to follow, or to be conceiv'd not to follow upon the other" (T 1.3.14.13; SBN 161-62). So, if my account of the complex perception of extension and its relation to its constituting simple perceptions is correct, then indeed, it is absolutely, or metaphysically, impossible to conceive the complex perception of extension and its properties without conceiving each and every simple perception composing it. Thus, this complex perception is absolutely, or metaphysically, necessarily connected to these simple perceptions. This result in the world of perceptions, to which I limit my discussion, may be generalised to concern any entity. To perceive is but to conceive. Thus, absolutely/metaphysically necessary connections between partially distinct entities are conceivable. By the conceivability principle, this entails that absolutely/metaphysically necessary connections between partially distinct entities other than perceptions are absolutely, or metaphysically, possible. However, it does not imply that such connections are possible between simple entities or amongst complex entities (causes and effects, for example), since if there are such entities, they are really distinct from each other. This result violates neither the separability principle nor the conceivability principle. The reason for this is that the separability principle applies, as I argued above, only to things that are really distinct, while the extension and the properties of the extension of a complex perception are not really distinct from the simple perceptions. Furthermore, as the partial distinction is not reciprocal, this type of necessary connection is not either. The simple perceptions of colors or tactile points are separable from their complex and conceivable without extension, as is evidenced by the fact that the perceptions of colored and tangible points do not, and cannot, present extension, location, and spatial relations in themselves.

This result notwithstanding, Hume’s tenet that there are no absolutely, or metaphysically, necessary connections between distinct entities still holds when it is restricted to cases where there is a real distinction. This can be shown by an indirect argument. Recall that if A and B are really distinct, then it is absolutely, or metaphysically, possible both that A exists without $\mathrm{B}$, and that B exists without $\mathrm{A}$. Let me assume, for the sake of the argument, that one of them is absolutely, or metaphysically, necessarily connected to the other. Then it is not absolutely or metaphysically possible that this entity exists without the other. Thus, by the definition of a real distinction, they cannot be really distinct from each other. The consequence is that there cannot be absolutely, or metaphysically, necessary connections between really distinct entities.

The opposite of Lewis's partial distinction is his "entire/whole distinction": $x$ and $y$ are entirely, or wholly, distinct if and only if they do not have any common part. ${ }^{34}$ Hume's real distinction could be understood as the entire, or whole, distinction because Humean really distinct entities cannot share parts, otherwise they would not be separable. So, the principle that there cannot be absolutely, or metaphysically, necessary connections between really 
distinct entities (simple perceptions of colored and tactile points, for example) could also be put in the following manner: there cannot be absolutely, or metaphysically, necessary connections between entirely, or wholly, distinct entities. However, for considerations of historical accuracy, it is preferable to use Hume's own terminology where possible. Thus, I have used the following combinations of traditional and contemporary terms to describe my account: real distinctions, partial distinctions, and distinctions of reason.

\section{Notes}

I would like to express my deepest gratitude to Professors Todd Ryan, Donald L. M. Baxter, Don Garrett, and the editors of Hume Studies for comments and corrections. Naturally, the anonymous referees made the paper much better. An earlier version of this paper was presented in the Nordic Workshop in Early Modern Philosophy III, University of Uppsala, Sweden, May 6, 2010. Writing this paper was made possible by funding from the Academy of Finland.

1 As is widely known, Hume holds that there are two kinds of perceptions: impressions and ideas. For the purposes of this paper, it suffices to say that sense perceptions are impressions, and thoughts about them are ideas.

2 I use "entity" in its etymological sense: it means an existing thing, a being.

3 References to Hume's Treatise are to A Treatise of Human Nature: A Critical Edition, ed. David Fate Norton and Mary J. Norton, 2 vols. (Oxford: Clarendon Press, 2007), hereafter cited as "T" followed by Book, part, section, and paragraph number; and to A Treatise of Human Nature, ed. L. A. Selby-Bigge, revised by P. H. Nidditch, 2nd ed. (Oxford: Clarendon Press, 1978), hereafter cited as "SBN," followed by page number.

4 Don Garrett, "Priority and Separability in Hume's Empiricism," Archiv fir Geschichte der Philosophie 67 (1984): 270-88, 270.

5 David Lewis, Papers in Metaphysics and Epistemology (Cambridge: Cambridge University Press, 1999), 177.

6 Richard Glauser, "Descartes, Suarez and the Theory of Distinctions," in The Philosophy of Marjorie Grene, ed. Randall E. Auxier and Lewis E. Hahn, The Library of Living Philosophers, Vol. 29 (Chicago: Open Court, 2002), 417-45, 419.

7 Francis Suarez, On the Various Kinds of Distinctions, trans. Cyril Vollert (Milwaukee: Marquette University Press, 2007), 1.9. References to Suarez are by section and clause number.

8 René Descartes, Principles of Philosophy, in The Philosophical Writings of Descartes, vol. 1, trans. John Cottingham, Robert Stoothoff, and Dugal Murdoch (Cambridge: Cambridge University Press, 1991), hereafter cited as Princ. followed by book and section number.

9 In Spinoza's mature writings, there is no systematic discussion of distinctions. In the Principia philosophiae cartesianae (1663), he more or less recapitulates Descartes's views. See Baruch Spinoza, Appendix containing Metaphysical Thoughts, in The Collected Works of Spinoza, ed. and trans. Edwin Curley, vol. 1 (Princeton: Princeton University Press, 1988), 323-25. Leibniz does not give any systematic account of distinctions as far as I know. 
10 Marilyn McCord Adams, William Ockham, vol. 1 (Notre Dame: University of Notre Dame Press, 1987), 17.

11 I take existential dependence/independence to be a type of ontological dependence/independence in addition to identity dependence /independence at least. Here it is not necessary to distinguish different types of the existential dependence/inde- pendence.

12 However, Suarez draws a distinction between the distinction of reasoning reason and the distinction of reasoned reason (distinctio rationis ratiocinantis vs. rationis ratiocinatae). The former has no foundation in reality, whereas the latter has some real basis (Suarez, 1.4). The real foundation does not imply, however, that the distinction is real because it still may be dependent on the intellect.

13 According to McCord Adams and King, Scotus calls these ways "realities"/"thinglets" (realitates), "formalities" (formalitates), "aspects" (rationes), "formal aspects" (rationes formales), "intensions" (intentiones), or "real aspects" (rationes reales). McCord Adams, William Ockham, 24, and Peter King, "Scotus on Metaphysics," in The Cambridge Companion to Duns Scotus, ed. Thomas Williams (Cambridge: Cambridge University Press, 2003), 15-67, 23.

14 For Hume's possible source of the scholastic discussion, see Ephraim Chambers, Cyclopaedia, Vol. 1 (London, 1728), 230.

15 Martha Brandt Bolton, “The Taxonomy of Ideas in Locke's Essay,” in The Cambridge Companion to Locke's Essay Concerning Human Understanding, ed. Lex Newman (Cambridge: Cambridge University Press, 2007), 67-100, 77.

16 The term "Conceivability Principle" comes from D. Tycerium Lightner, "Hume on Conceivability and Inconceivability,” Hume Studies 23 (1997): 113-32, 114.

17 There has been debate among Hume scholars about the exact nature of conceivability in the conceivability principle. Peter Millican has recently attacked Peter Kail's view that Hume restricts it to adequate conception vigorously. Peter Millican, "Hume, Causal Realism, and Causal Science,” Mind 118 (2009): 647-712, 676ff. Hume himself fuels this discussion because his formulations of the conceivability principle vary from clear and distinct, merely clear or separate conception, to bare conception (T 1.1.7.6, 1.2.4.11, 1.2.2.8, 1.4.5.5, App. 12, T 1.3.3.3; SBN 19, 43, 32, 233, 634, 79-80). For the present purposes, this debate is not relevant because the conceivability principle does not play such a major role in my argument.

18 It is not clear that Hume endorses the converse principle, that inconceivability implies impossibility, without specifying the reason for the inconceivability (for example, whether it involves contradiction or not). See T 1.2.2.1 (SBN 29).

19 References to Hume's first Enquiry are to David Hume, An Enquiry Concerning Human Understanding: A Critical Edition, ed. Tom L. Beauchamp (Oxford: Clarendon Press, 2000), cited as "EHU" followed by section and paragraph number; and Hume, Enquiries concerning Human Understanding and concerning the Principles of Morals, ed. L. A. Selby-Bigge, revised by P. H. Nidditch, 3rd ed. (Oxford: Clarendon Press, 1975), hereafter cited as "SBN" followed by page number.

20 "It cannot be doubted, that the mind is endowed with several powers and faculties, that these powers are distinct from each other, that what is really distinct to the immediate perception may be distinguished by reflection” (EHU 1.4; SBN 13-14). 
21 It should be realized, though, that distinction (numerical non-identity) is not a relation but a negation of relation on Hume's view. Hume is explicit about it in the following passage, where he uses "difference" as a synonym for "distinction" when he is speaking about difference as the opposite of numerical difference: "It might naturally be expected, that I should join difference to the other relations. But that I consider rather as a negation of relation, than as any thing real or positive. Difference is of two kinds as oppos'd either to identity or resemblance. The first is call'd a difference of number; the other of kind" (T 1.1.5.10; SBN 15).

22 Lorne Falkenstein, "Space and Time," in The Blackwell Guide to Hume's Treatise, ed. Saul Traiger (Oxford: Blackwell, 2006), 59-76.

23 At T 1.4.5.9 (SBN 235), Hume puts it beyond doubt that his view is that only sight or colors and touch or tactile qualities (temperature, hardness) can present extension to the mind: "The first notion of space and extension is deriv'd solely from the senses of sight and feeling; nor is there any thing, but what is colour'd or tangible, that has parts dispos'd after such a manner, as to convey that idea."

24 See also Don Garrett, Cognition and Commitment in Hume's Philosophy (Oxford: Oxford University Press, 1997), 61.

25 There is the complication that in this quote, Hume speaks about solidity instead of tangibility or tactile qualities. But here he must mean hardness rather than solidity proper (impenetrability), because just after the quote he argues that solidity proper cannot be felt by touch (T 1.4.4.13-14; SBN 230-31).

26 As Garrett stresses, in Hume's nominalist framework, there can be no genuinely general idea of extension: every perception of extension is a perception of some particular extended entity (Cognition, 61).

27 According to Falkenstein, this corresponds to the concept of a discrete space in mathematics: "A space is discrete only if (but not if), for any line in that space, every point on that line except the first (if there is one) has an immediate successor, and every point on that line except the last (if there is one) has an immediate predecessor, where "immediate" means that there are no other intervening points” (62-63).

28 Donald L. M. Baxter, "Hume’s Theory of Space and Time in Its Skeptical Context," in The Cambridge Companion to Hume, ed. David Fate Norton and Jacqueline Taylor, 2nd ed. (Cambridge: Cambridge University Press, 2009), 105-46, 131, 134.

29 This generalises the point to concern what Hume calls "natural relations" (association of perceptions), which are the opposite of "philosophical relations" that result from what the original point was: the comparison of ideas (T 1.1.5.1-2, 1.3.6.16; SBN 13-14, 94).

30 David Lewis, Papers in Metaphysics, 177.

31 Thus, this result may be generalized to concern every type of complex perception only if there is some relation that unifies them into individuals. If there is not that kind of relation, the complex perception is merely the simple perceptions composing it (their plurality). Then the complex perception is not partially distinct from this plurality, as they are identical. Yet it is partially distinct from each of the simple perceptions composing it, and the plurality in which at least one of them is missing. For example, let me assume that there is a complex perception that is nothing but three simple perceptions $\mathrm{A}, \mathrm{B}$, and C, i.e., their plurality. Then the complex perception is identical with the plurality of $\mathrm{A}, \mathrm{B}$, and $\mathrm{C}$ and not partially distinct from them. 
But it is partially distinct from the pluralities $\mathrm{A}$ and $\mathrm{B}, \mathrm{A}$ and $\mathrm{C}$, and the simple perceptions $\mathrm{A}, \mathrm{B}$, or $\mathrm{C}$. It is not identical with any of these five perceptions.

32 John W. Yolton, Realism and Appearances: An Essay in Ontology (Cambridge: Cambridge University Press, 2000), 99ff.

33 For the existence of the complex perception of extension and its proper parts, see $\mathrm{T}$ 1.2.3.14, 1.2.3.16, 1.2.4.2, 1.2.4.3 (SBN 38, 39, 40).

34 Lewis, Papers in Metaphysics, 177, and David Lewis, On the Plurality of Worlds (Oxford: Blackwell, 1986), 211. 